\title{
The Italian master Leonardo da Vinci and his early understanding of the brachial plexus
}

\author{
Chidinma Nwaogbe ${ }^{1} \cdot$ Anthony V. D'Antoni ${ }^{1} \cdot \operatorname{Rod}^{\prime}$. Oskouian ${ }^{2} \cdot$ R. Shane Tubbs ${ }^{2}$
}

Received: 13 August 2017 / Accepted: 21 August 2017 / Published online: 6 September 2017

(C) Springer-Verlag GmbH Germany 2017

\section{Introduction}

Leonardo di ser Piero da Vinci was born in the town of da Vinci, Republic of Florence, to a notary and a peasant woman. Although he is renowned primarily as a painter, and is still lauded today for works such as the Mona Lisa, The Last Supper, and the Vitruvian Man, he also contributed considerably to the discipline of anatomy [1]. da Vinci started his work in anatomy under the apprenticeship of Andrea del Verrocchio where he quickly developed skills in artistically depicting surface anatomy [2]. His development of this skill allowed him to dissect cadavers, depict their likeness, and take numerous notes on his observations. From his observations, he produced the first accurate depiction of the human spine, created the earliest known description of cirrhosis of the liver and atherosclerosis, and made discoveries about cardiac output and the aortic valve [3]. Being a skilled dissector and a detailed artist with an unquenchably curiosity made da Vinci a brilliant anatomist.

\section{Da Vinci on the brachial plexus}

One of his astounding - but lesser known-feats as an anatomist is his dissection and depiction of the brachial

R. Shane Tubbs

shanet@seattlesciencefoundation.org

CUNY School of Medicine, New York, NY 10031, USA

2 Seattle Science Foundation, 550 17th Ave Suite 600, Seattle, WA 98122, USA plexus (Fig. 1 and cover image). The brachial plexus is a complex and delicate network of nerves that extend from the spinal cord to the arm and innervate the upper limb [4]. His drawings of this structure began from crude depictions of canine upper limbs to a sophisticated demonstration of the complexity of the human upper limb [5]. The complexity of the upper limb, compounded with the fragility of the neural structures in this area, proved a source of challenge and occasional confusion for da Vinci, as his depiction of the plexus occasionally depicted four roots rather than the correct five, and displayed inaccurate placement of the sympathetic trunk [4]. As he created drawings of the upper limb, it is clear that his drawing and dissection skills improved greatly as he began to appreciate the transitional structure between spinal and peripheral nerves [5]. Ultimately, da Vinci's work was not limited to aesthetic exploration of the brachial plexus; his drawings, coupled with observations, enabled him to determine him the effect of lesions of different areas of the brachial plexus on sensation and functionality, providing insight to the field of anatomy and medicine that was far beyond his time [4-7].

Early drawings by da Vinci of the brachial plexus origin show only four roots contributing. However, with time, he showed vividly that the upper trunk of the brachial plexus is formed by $\mathrm{C} 5$ and $\mathrm{C} 6$ ventral rami, the middle trunk is a continuation of the $\mathrm{C} 7$ ventral ramus, and that the lower trunk is formed by the ventral rami of $\mathrm{C} 8$ and T1. Although not as accurate, his drawings do show the distal arrangement of the medial, lateral, and posterior cords of the brachial plexus [5]. Terminal branches of the plexus are also easily observed in some of his drawings of the brachial plexus including the radial, median, and ulnar arteries. Distally, in the hand, he depicted the cutaneous territories of the ulnar and median nerves for the digits by illustrating very precisely the ulnar 
Fig. 1 and cover image Drawings of the brachial plexus by Leonardo da Vinci (center top)

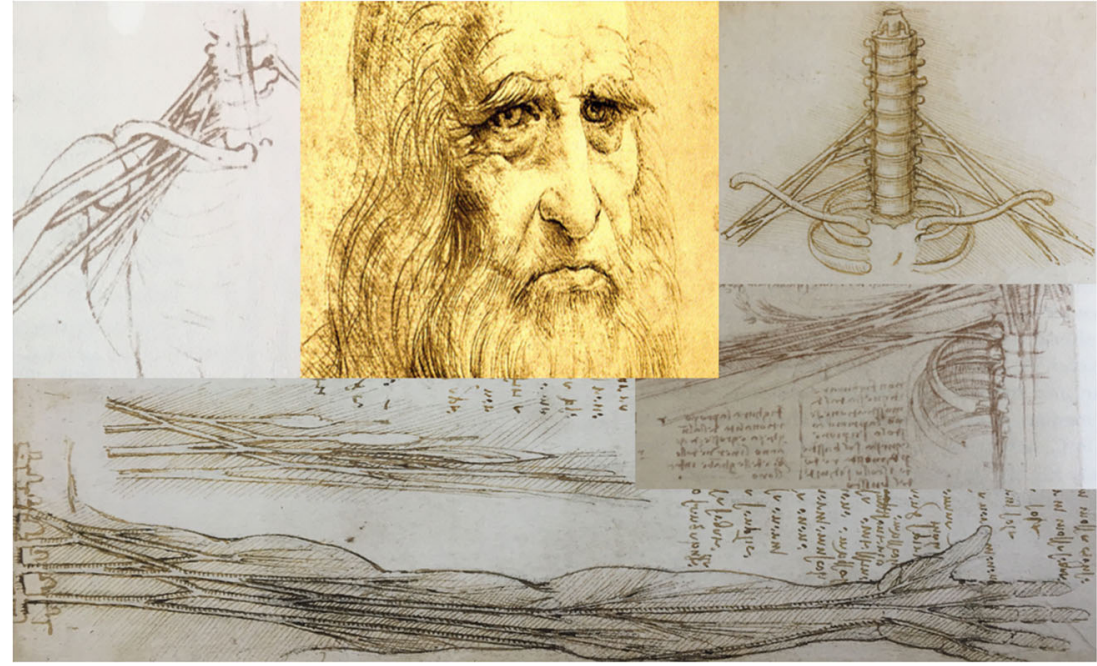

innervation of skin of the medial one and one half digits. Again, his understanding on the basic function of these nerves is shown by the following comments:

...is the nerve which gives sensation. This having been cut the finger no longer has sensation even when placed in the fire." "Following a cut in the hand, sometimes the sensation and not the motion of the finger is blocked, and sometimes the motion and not the sensation. Sometimes it is both motion and sensation." [5].

Da Vinci made some interesting comments in his notes on the brachial plexus as well with some of these demonstrating a knowledge of their physiology. For example, he stated, "Any one of the five branches saved from a sword cut is enough for sensation in the arm." [5] As an example of his interest in surgical anatomy of this region, he stated,

"...describe the distances interposed between nerves in depth as well as breadth and thus the proportions of their sizes and lengths and the differences between their heights and descents from their origins. You will do the same for muscles, veins, and arteries; and this will be most useful to those who treat wounds." [5].

\section{Conclusions}

Da Vinci's illustrations and descriptions of the brachial plexus set the stage for future scholars to better understand this complicated nervous structure. The brachial plexus continues to be of significant clinical interest [8-13] and thus our current knowledge of this structure was begun by the works of da Vinci in the fifteenth century.

\section{Compliance with ethical standards}

Conflict of interest The authors have no conflicts of interest.

\section{References}

1. Bambach C (2002) Leonardo da Vinci (1452-1519). In: Heilbrunn timeline of art history. Metropolitan Museum of art, New York. http:// www.metmuseum.org/toah/hd/leon/hd_leon.htm

2. Heydenreich LH (1998) Leonardo Da Vinci. In: Encyclopaedia Britannica. Encyclopaedia Britannica, Inc. https://www.britannica. com/biography/Leonardo-da-Vinci

3. Jones R (2012) Leonardo da Vinci: anatomist. Br J Gen Pract 62:319

4. Clayton M, Philo R (2012) The brachial plexus. In: Leonardo da Vinci, Anatomist. St. James Palace, London pp 114-121

5. Todd E (1981) The peripheral nerves and plexuses. In: The neuroanatomy of Leonardo da Vinci. Capra Press, Santa Barbara pp 133-143

6. Bowen G, Gonzales J, Iwanaga J, Fisahn C, Loukas M, Oskouian RJ, Tubbs RS (2017) Leonardo da Vinci (1452-1519) and his depictions of the human spine. Childs Nerv Syst. https://doi.org/10.1007/s00381017-3354-9

7. Tubbs RI, Gonzales J, Iwanaga J, Loukas M, Oskouian RJ, Tubbs RS (2017) The influence of ancient Greek thought on fifteenth century anatomy: Galenic influence and Leonardo da Vinci. Childs Nerv Syst. https://doi.org/10.1007/s00381-017-3462-6

8. Laumonerie P, LapĖgue F, Chantalat E, Sans N, Mansat P, Faruch M (2017) Description and ultrasound targeting of the origin of the suprascapular nerve. Clin Anat. https://doi.org/10.1002/ca.22936

9. Sulaiman S, Soames R, Lamb C (2015) Ulnar nerve cutaneous distribution in the palm: application to surgery of the hand. Clin Anat 28: $1022-1028$

10. Cesmebasi A, O'driscoll SW, Smith J, Skinner JA, Spinner RJ (2015) The snapping medial antebrachial cutaneous nerve. Clin Anat 28:872-877

11. Futterman B (2015) Analysis of the papal benediction sign: the ulnar neuropathy of St. Peter. Clin Anat 28:696-701

12. Won SY, Cho YH, Choi YJ, Favero V, Woo HS, Chang KY, Hu KS, Kim HJ (2015) Intramuscular innervation patterns of the brachialis muscle. Clin Anat 28:123-127

13. Leechavengvongs $\mathrm{S}$, Teerawutthichaikit $\mathrm{T}$, Witoonchart $\mathrm{K}$, Uerpairojkit C, Malungpaishrope K, Suppauksorn S, Chareonwat B (2015) Surgical anatomy of the axillary nerve branches to the deltoid muscle. Clin Anat 28:118-122 